\title{
Transcatheter versus surgical valve replacement for a failed pulmonary homograft in the Ross population
}

\author{
Khadija Alassas, MD, ${ }^{\mathrm{a}}$ Dania Mohty, MD, PhD, ${ }^{\mathrm{a}, \mathrm{d}}$ Marie Annick Clavel, DVM, PhD, ${ }^{\mathrm{e}}$ Aysha Husain, MD, ${ }^{\mathrm{a}}$ \\ Talal Hijji, MD, ${ }^{\mathrm{a}}$ Mansour Aljoufan, MD, ${ }^{\mathrm{b}}$ Zohair Alhalees, MD, ${ }^{\mathrm{c}}$ and Bahaa M. Fadel, $\mathrm{MD}^{\mathrm{a}}$
}

\section{ABSTRACT}

Background: Patients who undergo the Ross procedure are at increased risk of pulmonary valve (PV) homograft dysfunction. For those who require reintervention on the homograft, transcatheter PV replacement (tPVR) provides a less invasive therapeutic option than surgical PVR (sPVR). We examined the outcomes following tPVR versus sPVR in a cohort of patients who underwent the Ross procedure.

Methods: We performed a retrospective analysis of Ross patients age $\geq 14$ years who underwent tPVR $(n=47)$ or $\operatorname{sPVR}(n=41)$ at our institution. The patients' clinical and echocardiographic data were reviewed.

Results: Baseline parameters, including demographic data and left ventricular and right ventricular (RV) systolic function, were similar in the 2 groups. The mean follow-up was $56 \pm 24$ months for the tPVR group and $89 \pm 46$ months for the sPVR group $(P<.001)$. No procedure-related mortality was noted in either group. At 6-year follow-up, there was no significant between-group difference in event-free survival (tPVR, 79\% $\pm 7 \%$ vs sPVR, 91\% $\pm 4 \% ; P=.15$ ) or PV reintervention (tPVR, 26\% $\pm 9 \%$ vs sPVR, $8 \% \pm 5 \% ; P=.31$ ). PV-associated infective endocarditis (IE) was significantly more common with tPVR (tPVR, $13 \%$ vs sPVR, $0 \% ; P=.04$ ), with an annualized rate of $2.98 \%$ per patient-year. In addition, there was a trend toward more valve dysfunction following sPVR (sPVR, 67\% $\pm 8 \%$ vs tPVR, 35\% $\pm 8 \% ; P=.08$ ).

Conclusions: In Ross patients who require reintervention on the PV homograft, both TPVR and SPVR provide low procedural mortality and comparable midterm outcome with no significant difference in mortality or PV reintervention. However, IE is more common following tPVR. A larger randomized study is needed to determine the role of each procedure in patient management. ( $\mathrm{J}$ Thorac Cardiovasc Surg 2018;155:1434-44)

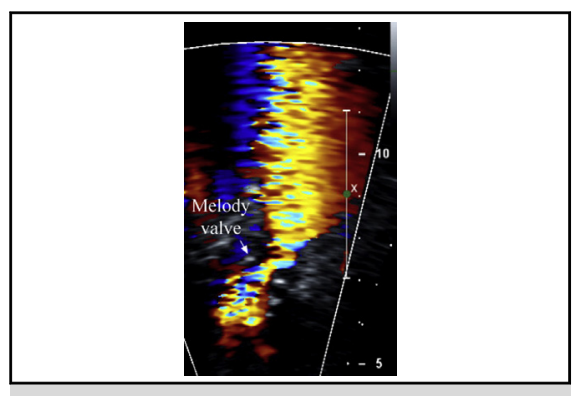

Severe regurgitation across a transcatheter pulmo nary valve prosthesis (Melody size 18)

\section{Central Message}

In patients who undergo the Ross procedure and require intervention on the pulmonary homograft, both transcatheter and surgical valve replacement provide low procedural mortality and comparable midterm outcomes.

\section{Perspective}

Patients who undergo the Ross procedure are at increased risk of pulmonary valve homograft dysfunction. Transcatheter pulmonary valve replacement provides a less invasive therapeutic option than surgery; however, outcome data for the transcatheter and surgical approaches in the Ross population are lacking. Assessment of the outcomes associated with both procedures is important for patient management.

See Editorial Commentary page 1445.
The Ross procedure, using a pulmonary autograft as a replacement for the aortic valve and a homograft in the pulmonary position, has emerged as an alternative to the use of prosthetic valves, particularly in the pediatric age group, owing to several advantages. It can be performed with low operative mortality, provides excellent hemodynamic characteristics of the autograft similar to

From the Sections of ${ }^{\mathrm{a}}$ Adult Cardiology, ${ }^{\mathrm{b}}$ Pediatric Cardiology, and ${ }^{\mathrm{c}}$ Cardiac Surgery, Heart Center, King Faisal Specialist Hospital and Research Center, Riyadh, Saudi Arabia; ${ }^{\mathrm{d} D e p a r t m e n t}$ of Cardiology, Dupuytren University Hospital, Limoges, France; and ${ }^{\mathrm{e}}$ Quebec Heart and Lung Institute, Quebec City, Quebec, Canada.

Read at the 97th Annual Meeting of The American Association for Thoracic Surgery, Boston, Massachusetts, April 29-May 3, 2017.

Received for publication May 3, 2017; revisions received Sept 29, 2017; accepted for publication Oct 30, 2017; available ahead of print Feb 1, 2018. those of native aortic valve, is associated with low rates of thrombogenicity and infective endocarditis (IE), and requires no anticoagulation, and the autograft has the potential for growth. ${ }^{1,2}$

A drawback to the Ross procedure is the degeneration of the pulmonary valve (PV) homograft with subsequent dysfunction in the form of stenosis and/or regurgitation. ${ }^{3-8}$

\footnotetext{
Address for reprints: Bahaa M. Fadel, MD, King Faisal Specialist Hospital \& Research Center, Heart Center, PO Box 3354, MBC 16, Riyadh 11211, Saudi Arabia (E-mail: fadelbahaa@gmail.com). $0022-5223 / \$ 36.00$

Copyright (C) 2017 by The American Association for Thoracic Surgery https://doi.org/10.1016/j.jtcvs.2017.10.141
} 

Abbreviations and Acronyms
$\mathrm{CI}=$ confidence interval
FAC $=$ fractional area change
$\mathrm{HR}=$ hazard ratio
IE $=$ infective endocarditis
MACE $=$ major adverse cardiac event
NYHA $=$ New York Heart Association
$\mathrm{PV}=$ pulmonary valve
PVR = pulmonary valve replacement
$\mathrm{RV} \quad=$ right ventricular
sPVR = surgical pulmonary valve replacement
TAPSE $=$ tricuspid annular plane systolic excursion
tPVR $=$ transcatheter pulmonary valve replacement
TTE $=$ transthoracic echocardiography

Scanning this $\mathrm{QR}$ code will take you to a supplemental video. To view the AATS Annual Meeting Webcast, see the URL next to the webcast thumbnail.

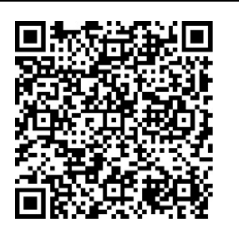

Severe and long-standing PV dysfunction may lead to right ventricular (RV) pressure and/or volume overload, with adverse effects on systolic function. In such patients, repeat PV surgery has traditionally been the sole available therapeutic option. In one study of a patient who underwent the Ross procedure, the cumulative incidence of reoperation on the PV homograft was $10.8 \%$ at 10 years and $35.5 \%$ at 20 years. ${ }^{3}$ Therefore, caretakers must balance the potential morbidity and mortality associated with a repeat surgical intervention-in the absence of a validated operative risk calculator for PV replacement-with the risk of progressive RV dysfunction if surgery is delayed or not envisioned.

Recent innovations in catheter and valve design have allowed for the emergence of transcatheter valve implantation as an alternative method of valve replacement. Transcatheter pulmonary valve replacement (tPVR) offers a less invasive substitute than surgical pulmonary valve replacement (sPVR) with the potential for lower periprocedural morbidity. tPVR is particularly attractive for Ross patients with isolated dysfunction of the homograft when a simultaneous intervention on the neoaortic valve is not required. Not surprisingly, the first case of tPVR in humans was performed in 2006 in a Ross patient with severe PV homograft stenosis. ${ }^{9}$ To date, no data are available regarding outcomes in tPVR versus sPVR in Ross patients.
The objective of this study was to perform a comparative analysis of such outcomes.

\section{METHODS \\ Patients and Study Protocol}

We performed a retrospective analysis of all patients age $\geq 14$ years who underwent a Ross procedure between 1990 and 2015. A total of 548 patients met these criteria. Of this group, 88 patients $(16 \%)$ with significant PV homograft dysfunction required an intervention on the homograft either as a tPVR or an sPVR. Forty-seven patients (53\%) underwent tPVR and 41 patients $(47 \%)$ underwent sPVR. These patients represent our study population. The indications for reintervention on the PV homograft were selected according to the guidelines for management of adults with congenital heart disease and included the following criteria: (1) severe homograft dysfunction in the form of stenosis and/or regurgitation associated with symptoms and (2) in the absence of symptoms, the development of progressive RV dilatation and/or dysfunction. ${ }^{10,11}$

The choice of tPVR or sPVR depended on the referring physician and patient preference. In patients with PV homograft dysfunction associated with significant dysfunction of the aortic autograft or mitral and/or tricuspid valve or coronary artery disease, sPVR was considered the procedure of choice. Repair and/or replacement of the other affected valve(s) or coronary bypass grafting was performed at the time of sPVR.

The study was conducted as part of the Valve Registry at our institution and was approved by the Institutional Ethics Committee.

\section{tPVR}

The protocol for tPVR has been detailed previously. ${ }^{1-13}$ All patients were given antibiotic prophylaxis (cephazolin $1 \mathrm{~g}$ intravenously) administered at the start of the procedure and at 8 and 16 hours afterward. Patients were started on low-dose aspirin following the procedure.

\section{SPVR}

Surgery was performed on cardiopulmonary bypass with aortic cannulation and a single venous cannula, unless concomitant tricuspid valve surgery was required. The procedure was done on a beating heart in the absence of intracardiac shunts. In the presence of a shunt, the aorta was cross-clamped, and the heart was arrested with cardioplegia. The existing pulmonary homograft was explanted, and the new homograft was then implanted.

\section{Echocardiography}

To assess the consequences of tPVR and SPVR on cardiac function, transthoracic echocardiography (TTE) were performed at preset intervals: within 1 month before the intervention, within 1 month after the intervention, and yearly thereafter unless clinical circumstances warranted more frequent assessment. All studies were performed using an E9 (General Electric, Milwaukee, Wis) or iE33 (Philips, Amsterdam, The Netherlands) cardiac ultrasound machine. The peak and mean PV gradients were obtained by continuous wave Doppler. The degree of PV regurgitation was assessed using color Doppler. ${ }^{14} \mathrm{RV}$ systolic function was evaluated based on several parameters: (1) tricuspid annular plane systolic excursion (TAPSE), (2) fractional area change (FAC), and (3) tissue Doppler-derived systolic $\left(\mathrm{S}^{\prime}\right)$ velocity of the RV free wall at the tricuspid annulus. ${ }^{15}$ Left ventricular ejection fraction was measured using the biplane Simpson method. Abnormal tPVR or sPVR function was defined as a peak PV gradient $\geq 36 \mathrm{~mm} \mathrm{Hg}$ and/or any regurgitation in the moderate or severe range. ${ }^{16}$

Echocardiographic criteria used for reintervention included severe tPVR stenosis, defined as a mean transpulmonary gradient $\geq 40 \mathrm{~mm}$ Hg. ${ }^{17}$ Severe regurgitation was defined by a multiparametric approach, 
including a ratio of regurgitant jet width/pulmonary annulus $>0.7$ with a deceleration time of the regurgitation spectral Doppler signal $<260 \mathrm{msec}$ and/or prominent holodiastolic reversal in the right pulmonary artery. ${ }^{14}$ Progressive increase in RV size with a basal diameter $>45 \mathrm{~mm}$ in the 4-chamber view together with a decrease in FAC to $<35 \%$, TAPSE $<16 \mathrm{~mm}$, and/or $\mathrm{S}^{\prime}$ velocity $\leq 9 \mathrm{~cm} /$ seconds were considered to represent $\mathrm{RV}$ dilatation and systolic dysfunction, respectively. ${ }^{15}$

\section{Statistical Analysis}

Patients were divided into 2 groups, tPVR and SPVR, according to the type of procedure performed. Continuous data were tested for normality by the Shapiro-Wilk test and are expressed as mean \pm standard deviation or median (interquartile range) as appropriate. Then differences between groups were tested using Student's $t$ test for normal variables and Kruskal-Wallis test for non-normal variables. Categorical data are presented as number and percentage and were compared using the $\chi^{2}$ test or Fisher's exact test as appropriate. Post hoc analysis between groups was performed using Bonferroni correction. The primary outcome was the occurrence of a major adverse cardiac event (MACE), including mortality, PV reintervention, and PV-associated IE. The follow-up time was calculated from the date of the procedure to the first event, death, or last available follow-up. The secondary endpoint was the rate of PV dysfunction, defined as at least moderate pulmonary regurgitation and/or stenosis on the last TTE.

To adjust for baseline differences between the 2 groups that could lead to a biased estimate of treatment effect, we computed an inverse probability of treatment weight estimator for each patient. The weighted variable method evaluates the probability of patients being included in 1 of the 2 groups and calculates weights based on factors hypothesized to influence group selection (ie, age, sex, body surface area, preoperative right heart failure, significant PV homograft dysfunction, baseline

TABLE 1. Demographic and baseline data of the tPVR and SPVR groups

\begin{tabular}{|c|c|c|c|c|}
\hline Parameter & $\begin{array}{c}\text { tPVR } \\
(n=47)\end{array}$ & $\begin{array}{c}\text { SPVR } \\
(n=41)\end{array}$ & $P$ value & Weighted $P$ value \\
\hline Age, $y$, mean \pm SD & $24 \pm 10$ & $27 \pm 11$ & .20 & .42 \\
\hline Male sex, $\mathrm{n}(\%)$ & $39(83)$ & $26(63)$ & .03 & .54 \\
\hline $\mathrm{BSA}, \mathrm{m}^{2}$, mean $\pm \mathrm{SD}$ & $1.7 \pm 0.4$ & $1.8 \pm 0.3$ & .1 & .29 \\
\hline Serum creatinine, $\mu \mathrm{mol} / \mathrm{L}$, median (IQR) & $76(66-84)$ & $75(64-92)$ & .83 & .90 \\
\hline \multicolumn{5}{|l|}{ NYHA functional class } \\
\hline I-II & 44 & 32 & .06 & .87 \\
\hline III-IV & 3 & 8 & & \\
\hline \multicolumn{5}{|c|}{ Etiology of AV disease before Ross procedure, $\mathrm{n}(\%)$} \\
\hline Rheumatic heart disease & $19(40)$ & $25(61)$ & .009 & .28 \\
\hline Congenital heart disease & $26(55)$ & $12(29)$ & & \\
\hline Infective endocarditis & $2(4)$ & $1(2)$ & & \\
\hline Other & $0(0)$ & $3(7)$ & & \\
\hline \multicolumn{5}{|c|}{ Type of valve dysfunction before Ross procedure, $\mathrm{n}(\%)$} \\
\hline Combined AS and AR & $8(17)$ & $11(27)$ & .02 & .43 \\
\hline Isolated AR & $21(45)$ & $23(56)$ & & \\
\hline Isolated AS & $18(38)$ & $6(15)$ & & \\
\hline Unknown & $0(0)$ & $1(2)$ & & \\
\hline \multicolumn{5}{|c|}{ Echocardiographic data at baseline } \\
\hline \multicolumn{5}{|c|}{ PV homograft dysfunction before reintervention, $\mathrm{n}(\%)$} \\
\hline Combined PS and PR & $29(66)$ & $17(41)$ & .02 & .68 \\
\hline Isolated PR & $6(9)$ & $15(37)$ & & \\
\hline Isolated PS & $12(23)$ & $5(12)$ & & \\
\hline None (IE) & $0(0)$ & $2(5)$ & & \\
\hline $\mathrm{PV}$ peak gradient, $\mathrm{mm} \mathrm{Hg}$, mean $\pm \mathrm{SD}$ & $68 \pm 27$ & $47 \pm 29$ & .0009 & .26 \\
\hline $\mathrm{PV}$ mean gradient, $\mathrm{mm} \mathrm{Hg}$, mean $\pm \mathrm{SD}$ & $38 \pm 16$ & $27 \pm 18$ & .001 & .32 \\
\hline \multicolumn{5}{|l|}{$\mathrm{RV}$ systolic parameters, mean $\pm \mathrm{SD}$} \\
\hline TAPSE, mm & $15 \pm 4$ & $16 \pm 3$ & .60 & .95 \\
\hline Tricuspid annular velocity $\left(\mathrm{S}^{\prime}\right), \mathrm{cm} / \mathrm{s}$ & $8 \pm 3$ & $9 \pm 2$ & .70 & .85 \\
\hline FAC, $\%$ & $45 \pm 13$ & $44 \pm 9$ & .70 & .38 \\
\hline \multicolumn{5}{|l|}{ Autograft function, $\mathrm{n}(\%)$} \\
\hline AS & $0(0)$ & $0(0)$ & .13 & .27 \\
\hline Mild or less AR & $40(85)$ & $26(63)$ & & \\
\hline Moderate AR & $6(13)$ & $6(15)$ & & \\
\hline Severe AR & $0(0)$ & $4(10)$ & & \\
\hline LVEF, $\%$, mean \pm SD & $53 \pm 11$ & $53 \pm 13$ & .80 & .94 \\
\hline
\end{tabular}

$\overline{t P V R}$, Transcatheter pulmonary valve replacement; $s P V R$, surgical pulmonary valve replacement; $S D$, standard deviation; $B S A$, body surface area; $I Q R$, interquartile range; $N Y H A$, New York Heart Association; $A V$, aortic valve; $A S$, aortic stenosis; $A R$, aortic regurgitation; $P V$, pulmonary valve; $P S$, pulmonary stenosis; $P R$, pulmonary regurgitation; $I E$, infective endocarditis; $R V$, right ventricular; TAPSE, tricuspid annular plane systolic excursion; $F A C$, fractional area change; $L V E F$, left ventricular ejection fraction. 
TABLE 2. Procedural data

\begin{tabular}{|c|c|}
\hline Type of intervention & Value \\
\hline \multicolumn{2}{|l|}{ tPVR } \\
\hline $\begin{array}{l}\text { Interval between Ross procedure and tPVR, } \mathrm{y} \\
\text { mean } \pm \mathrm{SD}\end{array}$ & $9.9 \pm 4.7$ \\
\hline \multicolumn{2}{|l|}{ Type and size of $\mathrm{tPV}, \mathrm{n}(\%)$} \\
\hline \multicolumn{2}{|l|}{ Melody (n=39) } \\
\hline Size 18 & $31(66)$ \\
\hline Size 20 & $3(6)$ \\
\hline Size 22 & $5(11)$ \\
\hline \multicolumn{2}{|l|}{ Edwards SAPIEN $(\mathrm{n}=8)$} \\
\hline Size 23 & $5(11)$ \\
\hline Size 26 & $3(6)$ \\
\hline \multicolumn{2}{|l|}{ sPVR } \\
\hline $\begin{array}{l}\text { Interval between Ross procedure and sPVR, y, } \\
\text { mean } \pm \mathrm{SD}\end{array}$ & $9.2 \pm 7.5$ \\
\hline \multicolumn{2}{|l|}{ Type and size of sPV, n (\%) } \\
\hline \multicolumn{2}{|l|}{ Homograft $(\mathrm{n}=38)$} \\
\hline Size $20-23$ & $7(17)$ \\
\hline Size $25-27$ & $25(61)$ \\
\hline Size $29-31$ & $6(15)$ \\
\hline \multicolumn{2}{|l|}{ Heterograft $(n=3)$} \\
\hline Trifecta & $2(5)$ \\
\hline Xenograft & $1(2)$ \\
\hline \multicolumn{2}{|l|}{ Concomitant procedures at time of sPVR, $\mathrm{n}(\%)$} \\
\hline Aortic valve surgery & $6(15)$ \\
\hline Mitral valve surgery & $5(12)$ \\
\hline Tricuspid valve surgery & $6(15)$ \\
\hline Multivalve surgery & $6(15)$ \\
\hline $\mathrm{C}$ coronary artery bypass grafting & $1(2)$ \\
\hline
\end{tabular}

$t P V R$, Transcatheter pulmonary valve replacement; $S D$, standard deviation; $t P V$, transcatheter pulmonary valve; $s P V R$, surgical pulmonary valve replacement; $s P V$, surgical pulmonary valve.

mean PV gradient, serum creatinine, hemoglobin, etiology of rheumatic heart disease, previous IE, and baseline New York Heart Association (NYHA) functional class > II). This method was then used for all analyses.

The cumulative probability of events was estimated using the weighted Kaplan-Meier method, and results are presented at 2 and 6 years postprocedure. A weighted log-rank test was used to test for significant differences in terms of MACE or tPVR or SPVR dysfunction between the 2 groups. Univariate and weighted univariate Cox proportional hazards analyses were performed to assess the associations between MACE and tPVR or SPVR dysfunction and the most clinically relevant variables, including age and the echocardiographic parameters known to affect survival, and the presence of concomitant procedures. A multivariate analysis was then performed using the clinically relevant variables and variables that reached $P<.10$ on weighted univariate Cox regression. A $P$ value $<.05$ was considered statistically significant. All statistical analyses were performed using JMP version 10.0.0 (SAS Institute, Cary, NC) and Stata 14 (StataCorp, College Station, Tex).

\section{RESULTS}

\section{Population Study}

Patient characteristics are summarized in Table 1. The mean patient age was $24 \pm 10$ years for the tPVR group and $27 \pm 11$ years for the sPVR group $(P=.42)$. The baseline characteristics did not differ significantly between the 2 groups (Table 1). There was no significant difference in the interval between the Ross procedure and tPVR or sPVR (mean, $9.9 \pm 4.7$ years vs $9.2 \pm 7.5$ years; $P=.60$ ) (Table 2). Most of the 47 patients who underwent tPVR received a Melody valve (Medtronic, Minneapolis, Minn). In the sPVR group, the majority of patients underwent reinsertion of a homograft. Twenty-four patients (59\%) had concomitant surgical intervention(s) at the time of sPVR, mostly for concomitant valvular disease (Table 2). The mean follow-up was $56 \pm 24$ months in the tPVR group and $89 \pm 46$ months in the sPVR group $(P<.001)$. The median echocardiographic follow-up was 63 months (range, 6-94 months) in the tPVR group and 99 months (range, 1-161 months) in the sPVR group.

\section{Periprocedural Outcomes}

Periprocedural data are listed in Table 3. The duration of hospitalization was shorter in the tPVR group, and transfusion of blood products was more common in the sPVR group. No procedural or 30-day mortality was noted in either group. Incidences of periprocedural and early complications are reported in Table 3.

\section{Early Hemodynamic Data}

Imaging and hemodynamic data obtained by TTE are listed in Table 3. TTE performed within 1 month of the intervention showed that tPVR and sPVR were similarly associated with an optimal hemodynamic result in approximately two-thirds of patients. Following the intervention, there was a significant decrease in the gradients across the PV prosthesis in both groups. A postprocedural suboptimal hemodynamic result was noted in one-third of patients in each group. Patients in the tPVR group had higher postprocedural peak and mean transpulmonary gradients, whereas those in the sPVR group had more pulmonary regurgitation $(P=.02)$. Furthermore, tPVR was associated with improvement of all RV systolic parameters (Table 3). In addition, the function of the aortic autograft remained stable following intervention on the pulmonary homograft, and no patient experienced new or worsening autograft dysfunction.

\section{Infective Endocarditis}

Episodes of IE were diagnosed according to the modified Duke criteria. ${ }^{18}$ TTE and transesophageal echocardiography were performed in all patients with suspected IE. Six patients $(13 \%)$ in the tPVR group were diagnosed with PV-associated IE (Video 1), compared with none in the sPVR group. The median interval between tPVR and IE was 68 months (range, 2-161 months). Three patients had isolated PV endocarditis, and the 3 other patients had multivalvular involvement: 1 each with pulmonary and mitral valve endocarditis; pulmonary, mitral, and aortic valve endocarditis; and 4-valve involvement. Three patients 
TABLE 3. Early and midterm outcomes

\begin{tabular}{|c|c|c|c|c|}
\hline Parameter & $\begin{array}{c}\text { tPVR } \\
(n=47)\end{array}$ & $\begin{array}{c}\text { SPVR } \\
(n=41)\end{array}$ & $P$ value* & Weighted $P$ value* \\
\hline Hospital stay, $d$, mean $\pm \mathrm{SD}$ & $3.1 \pm 2.5$ & $13.6 \pm 12.4$ & $<.0001$ & .004 \\
\hline Blood transfusion, $\mathrm{n}(\%)$ & $1(2)$ & $20(49)$ & $<.0001$ & .001 \\
\hline Transfusion of other blood products, $n(\%)$ & $1(2)$ & $20(51)$ & $<.0001$ & $<.0001$ \\
\hline \multicolumn{5}{|l|}{ Periprocedural complications, $\mathrm{n}(\%)$} \\
\hline Sternal wound infection & NA & $5(12)$ & - & - \\
\hline Femoral artery pseudoaneurysm & $1(2)$ & NA & - & - \\
\hline Femoral AV fistula & $1(2)$ & NA & - & - \\
\hline Stent fracture of prosthetic valve & $1(2)$ & NA & - & - \\
\hline Failure of tPV deployment & $1(2)$ & NA & - & - \\
\hline \multicolumn{5}{|l|}{ Midterm complications, n (\%) } \\
\hline Death & $2(4)$ & $1(2)$ & .99 & .97 \\
\hline IE involving PV & $6(13)$ & $0(0)$ & .12 & .04 \\
\hline Redo PV intervention & $10(21)$ & $5(12)$ & .04 & .31 \\
\hline SPVR & $2(4)$ & $2(5)$ & - & - \\
\hline tPVR & $4(9)$ & $3(7)$ & - & - \\
\hline Balloon valvuloplasty & $6(13)$ & $0(0)$ & - & - \\
\hline \multicolumn{5}{|l|}{ Echocardiographic data postintervention } \\
\hline tPV or sPV dysfunction $\geq$ moderate, $\mathrm{n}(\%)$ & $15(32)$ & $14(34)$ & .05 & .02 \\
\hline Isolated PR $\geq$ moderate, $\mathrm{n}(\%) \dagger$ & $0(0)^{*}$ & $5(12)^{*}$ & & \\
\hline High PV gradient, $\mathrm{n}(\%) \ddagger$ & $13(28)$ & $6(15)$ & & \\
\hline High PV gradient $+\geq$ moderate PR, n $(\%)$ & $2(4)$ & $3(7)$ & & \\
\hline $\mathrm{PV}$ peak gradient, $\mathrm{mm} \mathrm{Hg}$, mean $\pm \mathrm{SD}$ & $32 \pm 11$ & $24 \pm 20$ & .02 & $<.0001$ \\
\hline $\mathrm{PV}$ mean gradient, $\mathrm{mm} \mathrm{Hg}$, mean $\pm \mathrm{SD}$ & $17 \pm 6$ & $13 \pm 12$ & .07 & .001 \\
\hline \multicolumn{5}{|l|}{$\mathrm{RV}$ systolic parameters, mean $\pm \mathrm{SD}$} \\
\hline TAPSE, $\mathrm{mm}$ & $15 \pm 4$ & $13 \pm 4$ & .10 & .03 \\
\hline Tricuspid annular velocity $\left(\mathrm{S}^{\prime}\right), \mathrm{cm} / \mathrm{s}$ & $11 \pm 3$ & $7 \pm 2$ & .0001 & $<.0001$ \\
\hline FAC, $\%$ & $48 \pm 9$ & $41 \pm 11$ & .007 & .005 \\
\hline $\mathrm{LVEF}, \%$, mean $\pm \mathrm{SD}$ & $54 \pm 10$ & $49 \pm 11$ & .09 & .38 \\
\hline \multicolumn{5}{|l|}{ Echocardiographic data at last follow-up } \\
\hline tPV or sPV dysfunction $\geq$ moderate, $\mathrm{n}(\%)$ & $15(32)^{*}$ & $28(68)^{*}$ & .002 & .04 \\
\hline Isolated PR $\geq$ moderate, $\mathrm{n}(\%)$ & $0(0)^{*}$ & $13(32)^{*}$ & & \\
\hline High PV gradient, $\mathrm{n}(\%)_{\ddagger}^{\ddagger}$ & $13(28)$ & $8(20)$ & & \\
\hline High PV gradient $+\geq$ moderate PR, $\mathrm{n}(\%)$ & $2(4)$ & $7(17)$ & & \\
\hline $\mathrm{PV}$ peak gradient, $\mathrm{mm} \mathrm{Hg}$, mean $\pm \mathrm{SD}$ & $37 \pm 26$ & $36 \pm 27$ & .80 & .83 \\
\hline $\mathrm{PV}$ mean gradient, $\mathrm{mm} \mathrm{Hg}$, mean $\pm \mathrm{SD}$ & $22 \pm 15$ & $20 \pm 15$ & .50 & .34 \\
\hline \multicolumn{5}{|l|}{$\mathrm{RV}$ systolic parameters, mean $\pm \mathrm{SD}$} \\
\hline TAPSE, $\mathrm{mm}$ & $15 \pm 4$ & $15 \pm 4$ & .60 & .46 \\
\hline Tricuspid annular velocity $\left(\mathrm{S}^{\prime}\right), \mathrm{cm} / \mathrm{s}$ & $9 \pm 2$ & $8 \pm 2$ & .10 & .01 \\
\hline FAC, $\%$ & $43 \pm 15$ & $44 \pm 10$ & .70 & .85 \\
\hline $\mathrm{LVEF}, \%$, mean $\pm \mathrm{SD}$ & $55 \pm 8$ & $53 \pm 12$ & .30 & .73 \\
\hline
\end{tabular}

$t P V R$, Transcatheter pulmonary valve replacement; $s P V R$, surgical pulmonary valve replacement; $S D$, standard deviation; $N A$, not applicable; $A V$, arteriovenous; $t P V$, transcatheter pulmonary valve; $I E$, infective endocarditis; $P V$, pulmonary valve; $s P V$, surgical pulmonary valve; $P R$, pulmonary regurgitation; $R V$, right ventricular; $T A P S E$, tricuspid annular plane systolic excursion; $F A C$, fractional area change; $L V E F$, left ventricular ejection fraction. $* P$ values from univariate Cox analyses. $\dagger P<.05$ with Bonferroni correction. $\ddagger$ High PV gradient defined as a peak gradient $\geq 36 \mathrm{~mm} \mathrm{Hg}$.

$(50 \%)$ had negative serology and blood cultures, likely due to recent antibiotic use. Three patients $(50 \%)$ were successfully treated medically. One patient required surgical explantation and replacement of the PV prosthesis. Two other patients died after failure of medical therapy. The annualized rate of tPVR-associated IE was $2.98 \%$ per patient-year.

\section{PV Reintervention}

In the tPVR group, 10 patients $(21 \%)$ underwent reintervention on the prosthetic PV. Two of these patients had 2 interventions each. Two patients underwent surgical replacement of the tPVR, and 2 other patients had repeat tPVR in the form of a transcatheter valve-in-valve intervention. Another 6 patients underwent transcatheter 


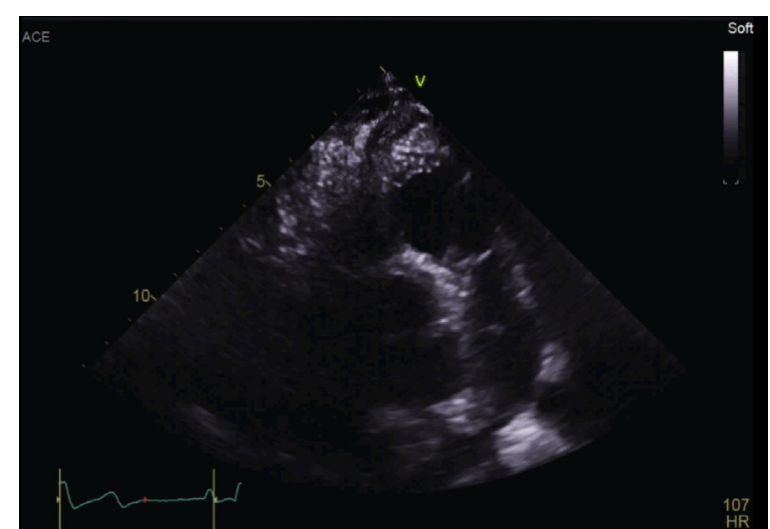

VIDEO 1. Transthoracic echocardiogram demonstrating a large and highly mobile mass on the transcatheter pulmonary valve prosthesis (Melody) suggestive of a vegetation. Video available at: http://www. jtcvsonline.org/article/S0022-5223(17)32770-8/fulltext.

balloon valvuloplasty of the tPVR due to severe stenosis. Two patients who required valvuloplasty later underwent repeat tPVR, bringing to 4 the total number of patients with redo tPVR. The median time to first reintervention in the tPVR group was 61 months (range, 0-82 months). In the sPVR group, 5 patients $(12 \%)$ required reintervention, including 2 patients with repeat sPVR and 3 patients with tPVR. The median interval to first reintervention in the sPVR group was 60 months (range, 12-128 months). There was no significant between-group difference in PV reintervention by weighted univariate analysis (tPVR, $26 \% \pm 9 \%$ vs sPVR, $8 \% \pm 5 \% ; P=.31$ ).

\section{Mortality}

Two patients died following tPVR due to IE. The intervals between tPVR and death were 16 months and 83 months. One patient died 111 months following sPVR. The cause of death was cardiogenic shock due to a concomitant dilated cardiomyopathy.

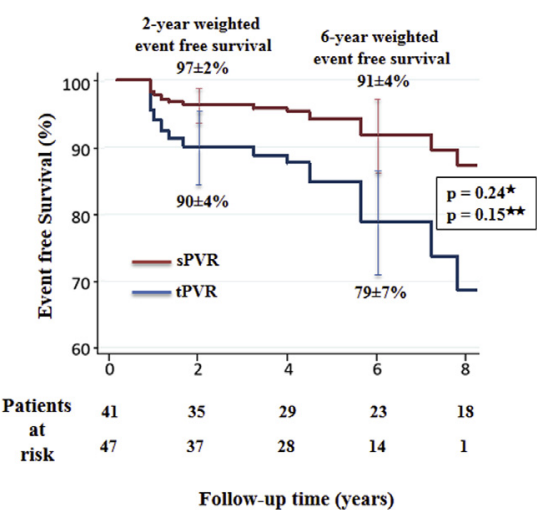

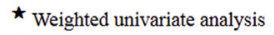

$\star \star$ Weighted mutivariate analysis

FIGURE 1. Event-free survival at 2 and 6 years according to the type of procedure, transcatheter pulmonary valve replacement $(t P V R)$ versus surgical pulmonary valve replacement $(s P V R)$.

\section{MACE}

Freedom from MACE at 2 years was $90 \% \pm 4 \%$ in the tPVR group and $97 \% \pm 2 \%$ in the sPVR group. At 6 years, freedom from MACE decreased to $79 \% \pm 7 \%$ and $91 \% \pm 4 \%$, respectively $(P=.24$ on weighted univariate analysis .15 on weighted multivariate analysis) (Figure 1 and Table 4). Freedom from PVR dysfunction at 2 years was $87 \% \pm 7 \%$ in the tPVR group and $64 \% \pm 9 \%$ in the sPVR group. At the 6-year follow-up, these values decreased to $75 \% \pm 10 \%$ and $42 \% \pm 12 \%$, respectively $(P=.04$ on weighted univariate analysis and .08 on weighted multivariate analysis) (Figure 2 and Table 5).

\section{Predictors of MACE}

Table 4 presents the univariate and multivariate markers associated with the occurrence of MACE. Age (hazard ratio [HR], 0.94; 95\% confidence interval [CI], 0.88-0.99; $P=.03$ ), male sex (HR, 6.71; 95\% CI, 1.14-39.24; $P=.04)$ and baseline RV function as expressed by TAPSE (HR, 1.70; 95\% CI, 1.07-2.71; $P=.03$ ) were significantly associated with a higher rate of MACE on weighted multivariate analysis. There was a trend toward an association between baseline NYHA functional class $\geq$ II (HR, 4.54; 95\% CI, 0.77-26.84; $P=.09$ ) and occurrence of MACE. The type of procedure (tPVR; HR, 4.07; $95 \%$ CI, 0.60-27.44; $P=.15$ ) and concomitant procedures at the time of sPVR showed no significant effect on the occurrence of MACE (Table 4).

\section{Predictors of PVR Dysfunction}

Table 5 presents the results of univariate and multivariate analyses of the parameters associated with PVR dysfunction. Baseline RV function as expressed by FAC (HR, 0.97; 95\% CI, 0.94-1.00; $P=.04$ ) was associated with PVR dysfunction at last follow-up on weighted multivariate analysis. Given that only 1 patient died without $\mathrm{PV}$ prosthesis dysfunction, the impact of death as a competing risk of PV dysfunction appears to be minimal.

\section{DISCUSSION}

This report presents the first study comparing outcomes of transcatheter versus surgical valve replacement of the dysfunctional PV homograft in patients who had undergone the Ross procedure. Our data suggest that both tPVR and SPVR carry low rates of procedural mortality and periprocedural complications. In addition, both appear to provide a reasonably good outcome at midterm follow-up, with no significant difference in combined MACE (mortality, PV reintervention, and PV endocarditis). However, when individual endpoints are considered, although mortality and PV reintervention continued to show no significant difference between the 2 groups, the 
TABLE 4. Univariate and multivariate analyses of markers associated with major adverse cardiac events

\begin{tabular}{|c|c|c|c|c|c|c|c|c|c|}
\hline \multirow[b]{2}{*}{ Variable } & \multicolumn{3}{|c|}{ Univariate analysis } & \multicolumn{3}{|c|}{ Weighted univariate analysis } & \multicolumn{3}{|c|}{ Weighted multivariate analysis } \\
\hline & $\overline{\text { HR }}$ & $95 \% \mathrm{CI}$ & $P$ value & HR & $\mathbf{9 5} \% \mathrm{CI}$ & $P$ value & HR & $95 \% \mathrm{CI}$ & $P$ value \\
\hline Age* & 0.94 & 0.89-1.00 & .05 & 0.94 & 0.88-0.99 & .03 & 0.91 & 0.84-0.99 & .03 \\
\hline Male sex & 2.60 & 0.74-9.18 & .14 & 3.19 & $0.82-12.32$ & .09 & 6.71 & $1.14-39.24$ & .04 \\
\hline $\mathrm{BSA}^{*}$ & 0.36 & $0.08-1.65$ & .19 & 1.07 & $0.14-8.47$ & .95 & - & - & - \\
\hline BMI* & 0.95 & $0.88-1.03$ & .24 & 0.99 & $0.92-1.07$ & .84 & - & - & - \\
\hline Underlying etiology $\dagger$ & 0.75 & $0.29-1.95$ & .55 & 0.86 & $0.27-2.79$ & .80 & - & - & - \\
\hline Previous IE & 1.31 & $0.30-5.86$ & .72 & 1.40 & $0.30-6.57$ & .67 & - & - & \\
\hline NYHA functional class $\geq$ II & 3.05 & $0.87-10.71$ & .08 & 4.90 & $1.26-19.04$ & .02 & 4.54 & $0.77-26.84$ & .09 \\
\hline Hemoglobin* & 1.00 & $0.98-1.03$ & .86 & 0.99 & $0.98-1.02$ & .87 & - & - & \\
\hline GFR* & 1.00 & $0.98-1.01$ & .59 & 1.00 & $0.99-1.02$ & .41 & - & - & - \\
\hline Baseline peak PV gradient* & 1.01 & $0.99-1.03$ & .3 & 1.00 & $0.98-1.02$ & .99 & - & - & - \\
\hline Baseline mean PV gradient ${ }^{*}, \ddagger$ & 1.00 & $0.98-1.04$ & .55 & 0.99 & $0.97-1.02$ & .46 & - & - & - \\
\hline TAPSE* & 1.13 & $0.92-1.37$ & .25 & 1.22 & $1.05-1.42$ & .009 & 1.70 & 1.07-2.71 & .03 \\
\hline FAC $^{*}$ & 1.00 & $0.96-1.06$ & .70 & 1.02 & $0.97-1.07$ & .48 & - & - & - \\
\hline LVEF* & 1.00 & $0.95-1.06$ & .91 & 0.98 & $0.93-1.03$ & .44 & - & - & - \\
\hline Concomitant procedures $\S$ & 0.71 & $0.26-1-97$ & .51 & 0.46 & $0.15-1.45$ & .18 & 0.78 & $0.09-6.99$ & .82 \\
\hline tPVR $\|$ & 5.16 & $1.57-23.63$ & .007 & 2.60 & $0.51-13.03$ & .24 & 4.07 & $0.60-27.44$ & .15 \\
\hline
\end{tabular}

Markers included in the multivariate analysis model are shown in bold type. $H R$, Hazard ratio; $C I$, confidence interval; $B S A$, body surface area ( ${ }^{2}$ ); $B M I$, body mass index $\left(\mathrm{kg} / \mathrm{m}^{2}\right) ; I E$, infective endocarditis; NYHA, New York Heart Association; GFR, glomerular filtration rate (mL/min); PV, pulmonary valve; TAPSE, tricuspid annular plane systolic excursion (mm); $F A C$, fractional area change $(\%) ; L V E F$; left ventricular ejection fraction $(\%) ; t P V R$, transcatheter pulmonary valve replacement. *Per unit increase. $\dagger$ Rheumatic valvular disease versus other etiologies. $\ddagger$ PV gradients are expressed in mm Hg. $\S$ Including mitral valve surgery, aortic valve surgery, tricuspid valve surgery, multivalve surgery, and/or coronary artery bypass surgery. \|Compared with surgical pulmonary valve replacement.

rate of PV endocarditis was significantly higher in the tPVR group.

The higher-than-expected rate of tPVR-associated IE has been reported by other groups. ${ }^{19-22}$ In one study including 311 patients, the annualized rate of a first episode of tPVR-associated IE was $0.88 \%$ per patient-year. ${ }^{19}$ The reason for the high rate of tPVR-associated IE remains unclear. ${ }^{20}$ Various factors have been suggested, including

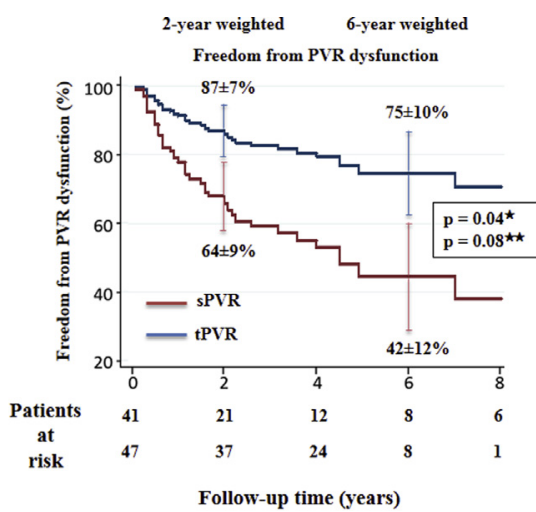

$\star$ Weighted univariate analysis

$\star \star$ Weighted mutivariate analysis

FIGURE 2. Freedom from pulmonary valve dysfunction at 2 and 6 years according to the type of procedure. $P V R$, Pulmonary valve replacement; $s P V R$, surgical pulmonary valve replacement; $t P V R$, transcatheter pulmonary valve replacement. friction between the PV and conduit, irregular geometry of the PV, incomplete apposition of the PV against the conduit, presence of underlying PV stenosis, lack of valve endothelialization, and formation of small thrombi on the prosthesis. ${ }^{19,20}$ Interestingly, a higher incidence of IE has been reported with use of the Contegra bovine jugular vein conduit, a surgical equivalent of the Melody valve that was used in most of our tPVR patients. ${ }^{23,24}$ The higher rate of IE noted in our study might be related to the low socioeconomic status and poor dental hygiene in our patient population. Conversely, no sPVR-associated IE was noted in our series, concurring with published data indicating a low rate of homograft IE in the Ross population. ${ }^{3,6}$

The mortality rate for tPVR-associated IE in our study is higher than reported by other groups (up to $12.5 \%$ ), possibly due to the multivalvular involvement and late presentation of our patients. ${ }^{19,20}$ Importantly, prostheses in the pulmonary position are often less well visualized than those in other valve positions by both TTE and transesophageal echocardiography. This could lead to a delay in establishing a diagnosis of IE and initiating therapy.

Our data show a trend toward a higher rate of PV dysfunction with sPVR despite the lack of a significant between-group difference in the rate of PV reintervention. This finding is corroborated by a large study including 
TABLE 5. Univariate and multivariate analyses of markers associated with pulmonary valve prosthesis dysfunction

\begin{tabular}{|c|c|c|c|c|c|c|c|c|c|}
\hline \multirow[b]{2}{*}{ Variable } & \multicolumn{3}{|c|}{ Univariate analysis } & \multicolumn{3}{|c|}{ Weighted univariate analysis } & \multicolumn{3}{|c|}{ Weighted multivariate analysis } \\
\hline & $\overline{\text { HR }}$ & $\mathbf{9 5} \% \mathrm{CI}$ & $P$ value & HR & $\mathbf{9 5} \% \mathrm{CI}$ & $P$ value & HR & $95 \% \mathrm{CI}$ & $P$ value \\
\hline Age* & 0.98 & 0.95-1.02 & .33 & 0.95 & 0.92-0.99 & .04 & 0.97 & $0.93-1.0$ & .05 \\
\hline Male sex & 0.98 & $0.49-1.98$ & .96 & 1.39 & $0.57-3.37$ & .60 & - & - & - \\
\hline $\mathrm{BSA}^{*}$ & 1.47 & $0.53-4.12$ & .46 & 1.91 & $0.53-6.85$ & .32 & - & - & - \\
\hline BMI* & 1.03 & 0.9-1.07 & .08 & 1.02 & $0.98-1.07$ & .25 & - & - & - \\
\hline Underlying etiology $\dagger$ & 1.78 & $0.93-3.38$ & .08 & 1.32 & $0.57-3.06$ & .50 & - & - & - \\
\hline Previous IE & 1.25 & $0.48-3.21$ & .65 & 1.28 & $0.62-2.67$ & .50 & - & - & - \\
\hline NYHA functional class $\geq$ II & 1.06 & $0.44-2.54$ & .89 & 0.48 & $0.17-1.42$ & .19 & 1.04 & $0.37-2.88$ & .94 \\
\hline Hemoglobin* & 0.99 & $0.98-1.01$ & .83 & 1.00 & $0.98-1.01$ & .99 & - & - & - \\
\hline GFR* & 1.00 & $0.99-1.01$ & .64 & 1.00 & $1.00-1.02$ & .16 & 1.01 & $1.00-1.03$ & .09 \\
\hline Baseline peak PV gradient*, $\ddagger$ & 0.99 & $0.98-1.01$ & .45 & 0.99 & $0.98-1.01$ & .35 & - & - & - \\
\hline Baseline mean PV gradient ${ }^{*}, \ddagger$ & 0.99 & $0.97-1.01$ & .21 & 0.98 & 0.96-1.00 & .06 & 0.96 & 0.94-0.99 & .08 \\
\hline TAPSE* & 1.11 & $0.98-1.26$ & .11 & 1.09 & $0.92-1.28$ & .30 & - & - & - \\
\hline $\mathrm{S}$ wave & 1.24 & $0.98-1.56$ & .07 & 1.23 & $0.89-1.70$ & .20 & - & - & - \\
\hline FAC* & 0.98 & $0.95-1.01$ & .21 & 0.97 & 0.94-1.00 & .07 & 0.97 & $0.94-1.00$ & .04 \\
\hline LVEF* & 1.01 & $0.97-1.05$ & .71 & 1.00 & $0.95-1.04$ & .85 & - & - & - \\
\hline sPVR $\S$ & 2.55 & $1.31-4.96$ & .002 & 2.37 & $1.06-5.33$ & .04 & 2.76 & $0.87-8.78$ & .08 \\
\hline
\end{tabular}

Markers included in the multivariate analysis model are shown in bold type. $H R$, Hazard ratio; $C I$, confidence interval; $B S A$, body surface area ( $\mathrm{m}^{2}$ ); $B M I$, body mass index $\left(\mathrm{kg} / \mathrm{m}^{2}\right) ; I E$, infective endocarditis; NYHA, New York Heart Association; GFR, glomerular filtration rate (mL/min); $P V$, pulmonary valve; TAPSE, tricuspid annular plane systolic excursion $(\mathrm{mm}) ; F A C$, fractional area change $(\%) ; L V E F$; left ventricular ejection fraction $(\%)$; $s P R$, surgical pulmonary valve replacement. $*$ Per unit increase. $\dagger$ Rheumatic valvular disease versus other etiologies. $\downarrow$ PV gradients are expressed in $\mathrm{mm} \mathrm{Hg}$. $\S$ Compared with transcatheter pulmonary valve replacement.

1642 Ross patients that demonstrated a $0.65 \%$ per patientyear risk of reintervention on the pulmonary homograft. ${ }^{25} \mathrm{~A}$ possible explanation for this finding is that PV homograft dysfunction most often manifests as regurgitation, which is usually well tolerated through the midterm duration of our study.

An additional finding in our study is that RV dysfunction as expressed by TAPSE is associated with an increased risk of MACE. This result agrees with published data demonstrating the negative impact of RV dysfunction on outcome. ${ }^{26}$ Moreover, age and NYHA class $\geq$ II tended to be associated with a higher risk of MACE. These findings suggest the need to intervene on the dysfunctional PV homograft before the development of advanced symptoms and/or RV dysfunction, particularly in the older age group.

To our knowledge, there are no published data addressing the outcomes of redo PV homograft surgery in the Ross population. In one published report that examined the outcome in a congenital cohort of patients (age 5 days to 16.9 years) who underwent redo $\mathrm{PV}$ homograft replacement, freedom from death and surgical or catheter intervention was $89 \%$ at 5 years and $76 \%$ at 10 years after surgery. ${ }^{27}$ These data are similar to the findings in our sPVR group.

There are no data to support the idea that a particular type of PV prosthesis provides an optimal platform for future tPVR. The circular shape of the RV outflow tract in Ross patients is believed to provide a favorable anatomic substrate that may increase the likelihood of optimal deployment of a future transcatheter valve and thus may improve procedural success. ${ }^{28}$ In our practice, we use PV homografts as the preferred choice for valve replacement in the pulmonary position.

In summary, our study suggests that neither type of intervention on the PV homograft in Ross patients, whether transcatheter or surgical, is superior to the other in terms of MACE, except for the higher rate of IE in the tPVR group. The decision regarding the choice of intervention on the PV homograft should be individualized and made by a multidisciplinary team that includes a cardiac surgeon and an expert in interventional structural cardiology. In patients who require additional surgery on other valves or cardiac structures, sPVR is the optimal approach. Conversely, in patients with isolated PV homograft dysfunction, tPVR provides a less invasive and promising therapeutic alternative to surgery, albeit at a higher risk of IE.

In addition to its retrospective design, an important limitation of our study is the relatively small sample size in both the tPVR and SPVR groups (owing to the rarity of interventions on the PV homograft in the Ross population), leading to a lower number of adverse events and reducing the study's statistical power. Limitations aside, our series represents the first comparison of transcatheter versus 
surgical replacement. Another limitation is that our patients were not randomized to type of intervention, with the choice of referral depending on physician and patient preference and on the presence of concomitant valvular or coronary artery disease. We performed an inverse propensity score weighted analysis to circumvent some of the foregoing limitations and to adjust for differences in baseline characteristics between the tPVR and SPVR groups.

An additional limitation involves our inclusion of patients with abnormally elevated PV gradients following tPVR and SPVR in whom we were unable to distinguish between organic stenosis due to valve degeneration and patient-prosthesis mismatch. Unfortunately, no published criteria are available for the diagnosis of patient-prosthesis mismatch in the pulmonary position; therefore, we considered any peak transpulmonary gradient $\geq 36 \mathrm{~mm} \mathrm{Hg}$ as abnormal irrespective of the underlying mechanism.

Regarding our endpoints, these differed from the Valve Academic Research Consortium criteria that have been established for transcatheter aortic valve replacement, including mortality, myocardial infarction, stroke, bleeding, acute kidney injury, vascular complications, and prosthetic valve performance. These criteria have not been validated for tPVR, and some of the endpoints, including myocardial infarction, stroke, and acute kidney injury, apply more to left-sided valve procedures, particularly in an older patient population. None of our patients experienced any of the 3 foregoing complications. In addition, because we assessed both periprocedural and midterm outcomes, we added IE as an endpoint. One final limitation is that our data might not apply to children age $<14$ years, given that all of our patients were older.

\section{CONCLUSIONS}

Our midterm data on clinical and hemodynamic outcomes in Ross patients who underwent transcatheter versus surgical replacement of PV homografts suggest no clear advantage of one approach over the other. Larger randomized prospective studies are needed to confirm our findings.

\section{Webcast}

You can watch a Webcast of this AATS meeting presentation by going to: https://aats.blob.core.windows. net/media/17AM/2017-05-02/BallroomABC/05-02-17_ BallroomABC_1650_Alassas.mp4.

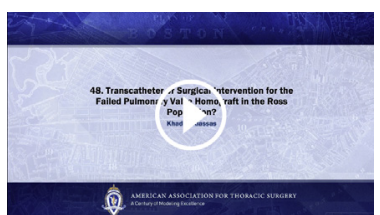

\section{Conflict of Interest Statement}

Authors have nothing to disclose with regard to commercial support.

We thank the staff of the echocardiography laboratory, catheterization laboratory, and cardiac surgery operating room at the King Faisal Specialist Hospital and Research Center.

\section{References}

1. Karamlou T, Jang K, Williams WG, Caldarone CA, Van Arsdell G, Coles JG, et al. Outcomes and associated risk factors for aortic valve replacement in 160 children: a competing-risks analysis. Circulation. 2005; 112:3462-9.

2. Henaine R, Roubertie F, Vergnat M, Ninet J. Valve replacement in children: a challenge for a whole life. Arch Cardiovasc Dis. 2012;105:517-28.

3. Schneider AW, Putter H, Klautz RJ, Bruggemans EF, Holman ER, Bökenkamp R, et al. Long-term follow-up after the Ross procedure: a single center 22-year experience. Ann Thorac Surg. 2017;103:1976-83.

4. Stulak JM, Burkhart HM, Sundt TM III, Connolly HM, Suri RM, Schaff HV, et al. Spectrum and outcome of reoperations after the Ross procedure. Circulation. 2010;122:1153-8.

5. Lenart-Migdalska A, Smaś-Suska M, Knap K, Kaźnica-Wiatr M, Olszowska M, Podolec P, et al. Long-term follow-up after the Ross procedure. J Rare Cardiovasc Dis. 2016;3:9-13.

6. Settepani F, Kaya A, Morshuis WJ, Schepens MA, Heijmen RH, Dossche KM The Ross operation: an evaluation of a single institution's experience. Ann Thorac Surg. 2005;79:499-504.

7. Hörer J, Hanke T, Stierle U, Takkenberg JJ, Bogers AJ, Hemmer W, et al. Homograft performance in children after the Ross operation. Ann Thorac Surg. 2009;88:609-15.

8. Feier H, Collart F, Ghez O, Riberi A, Caus T, Kreitmann B, et al. Risk factors, dynamics, and cutoff values for homograft stenosis after the Ross procedure. Ann Thorac Surg. 2005;79:1669-75; discussion 1675.

9. Garay F, Webb J, Hijazi ZM. Percutaneous replacement of pulmonary valve using the Edwards-Cribier percutaneous heart valve: first report in a human patient. Catheter Cardiovasc Interv. 2006;67:659-62.

10. Warnes CA, Williams RG, Bashore TM, Child JS, Connolly HM, Dearani JA, et al. ACC/AHA 2008 Guidelines for the management of adults with congenital heart disease: Executive summary: a report of the American College of Cardiology/American Heart Association Task Force on practice guidelines. Circulation. 2008;118:2395-451.

11. Ghawi H, Kenny D, Hijazi ZM. Transcatheter pulmonary valve replacement. Cardiol Ther. 2012;1:5.

12. Zahn EM, Hellenbrand WE, Lock JE, McElhinney DB. Implantation of the Melody transcatheter pulmonary valve in patients with a dysfunctional right ventricular outflow tract conduit: early results from the U.S. clinical trial. J Am Coll Cardiol. 2009;54:1722-9.

13. Khambadkone S, Coats L, Taylor A, Boudjemline Y, Derrick G, Tsang V, et al. Percutaneous pulmonary valve implantation in humans: results in 59 consecutive patients. Circulation. 2005;112:1189-97.

14. Zoghbi WA, Adams D, Bonow RO, Enriquez-Sarano M, Foster E, Grayburn PA, et al. Recommendations for noninvasive evaluation of native valvular regurgitation: a report from the American Society of Echocardiography developed in collaboration with the Society for Cardiovascular Magnetic Resonance. J Am Soc Echocardiogr. 2017;30:303-71.

15. Rudski LG, Lai WW, Afilalo J, Hua L, Handschumacher MD, Chandrasekaran K, et al. Guidelines for the echocardiographic assessment of the right heart in adults: a report from the American Society of Echocardiography endorsed by the European Association of Echocardiography, a registered branch of the European Society of Cardiology, and the Canadian Society of Echocardiography. J Am Soc Echocardiogr. 2010;23:685-713

16. Zoghbi WA, Chambers JB, Dumesnil JG, Foster E, Gottdiener JS, Grayburn PA, et al. Recommendations for evaluation of prosthetic valves with echocardiography and doppler ultrasound: a report from the American Society of Echocardiography's Guidelines and Standards Committee and the Task Force on Prosthetic Valves, developed in conjunction with the American College of Cardiology Cardiovascular Imaging Committee, Cardiac Imaging Committee of the American Heart Association, the European Association of 
Echocardiography, the Japanese Society of Echocardiography and the Canadian Society of Echocardiography. J Am Soc Echocardiogr. 2009;22:975-1014. quiz 1082-4.

17. Baumgartner H, Hung J, Bermejo J, Chambers JB, Evangelista A, Griffin BP, et al. Echocardiographic assessment of valve stenosis: EAE/ASE recommendations for clinical practice. J Am Soc Echocardiogr. 2009;22:1-23.

18. Li JS, Sexton DJ, Mick N, Nettles R, Fowler VG Jr, Ryan T, et al. Proposed modifications to the Duke criteria for the diagnosis of infective endocarditis. Clin Infect Dis. 2000;30:633-8.

19. McElhinney DB, Benson LN, Eicken A, Kreutzer J, Padera RF, Zahn EM. Infective endocarditis after transcatheter pulmonary valve replacement using the Melody valve: combined results of 3 prospective North American and European studies. Circ Cardiovasc Interv. 2013;6:292-300.

20. Amat-Santos IJ, Ribeiro HB, Urena M, Allende R, Houde C, Bédard E, et al. Prosthetic valve endocarditis after transcatheter valve replacement: a systematic review. JACC Cardiovasc Interv. 2015;8:334-46.

21. Gillespie MJ, Rome JJ, Levi DS, Williams RJ, Rhodes JF, Cheatham JP, et al. Melody valve implant within failed bioprosthetic valves in the pulmonary position: a multicenter experience. Circ Cardiovasc Interv. 2012;5:862-70.

22. Butera G, Milanesi O, Spadoni I, Piazza L, Donti A, Ricci C, et al. Melody transcatheter pulmonary valve implantation. Results from the registry of the Italian Society of Pediatric Cardiology. Catheter Cardiovasc Interv. 2013;81: 310-6.

23. Albanesi F, Sekarski N, Lambrou D, Von Segesser LK, Berdajs DA. Incidence and risk factors for Contegra graft infection following right ventricular outflow tract reconstruction: long-term results. Eur J Cardiothorac Surg. 2014;45:1070-4.

24. Ugaki S, Rutledge J, Al Aklabi M, Ross DB, Adatia I, Rebeyka IM. An increased incidence of conduit endocarditis in patients receiving bovine jugular vein grafts compared to cryopreserved homograft for right ventricular outflow reconstruction. Ann Thorac Surg. 2015;99:140-6.

25. Charitos EI, Takkenberg JJ, Hanke T, Gorski A, Botha C, Franke U, et al. Reoperations on the pulmonary autograft and pulmonary homograft after the Ross procedure: an update on the German-Dutch Ross Registry. J Thorac Cardiovasc Surg. 2012;144:813-21; discussion 821-3.

26. Haddad F, Couture P, Tousignant C, Denault AY. The right ventricle in cardiac surgery, a perioperative perspective: I. Anatomy, physiology, and assessment. Anesth Analg. 2009;108:407-21.

27. Bielefeld MR, Bishop DA, Campbell DN, Mitchell MB, Grover FL, Clarke DR. Reoperative homograft right ventricular outflow tract reconstruction. Ann Thorac Surg. 2001;71:482-7; discussion 487-8.

28. Nordmeyer J, Lurz P, Tsang VT, Coats L, Walker F, Taylor AM, et al. Effective transcatheter valve implantation after pulmonary homograft failure: a new perspective on the Ross operation. J Thorac Cardiovasc Surg. 2009;138:84-8.

Key Words: Ross procedure, reintervention, transcatheter pulmonary replacement, outcome

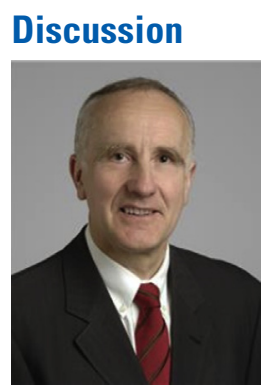

Dr G. Pettersson (Cleveland, Ohio). Thank you to the Association for the privilege of discussing this paper, and congratulations to Dr Alassas and the Riyadh group. The Riyadh group is one of the largest centers when it is comes to the Ross procedure, and your overall experience is impressive. You perform about 35 Ross procedures per year.

We all know that an Achilles' heel of the Ross procedure is the pulmonary homograft, and it is really good news that we can deal with the homograft problems percutaneously, even if you come out in the end that the major adverse events are still more in the surgical group. That's a little bit of a contradictory final conclusion that you arrive at. I still think that you have proven that this works, and it is also obvious that the durability of the percutaneous intervention is better than all the others.

Let's first talk about your incidence of homograft degeneration. Sixteen percent is high. I was just sitting behind Dr El Khoury. He has had a 16-year freedom from pulmonary valve degeneration of $93 \%$. So why is this? You have a high percentage of congenital patients in your group and you also have rheumatic valve disease. Do you have any explanation for this?

Dr Alassas. It could be the younger age group of our population that predisposes them to faster degeneration of the pulmonary homografts. Rheumatic heart disease showed that there was a trend toward significance in the univariate analysis that was not significant when entered in the multivariate analysis model, but still we cannot confirm or reject this theory because of the small number of patients.

Dr Pettersson. Second is, of course, the problem of endocarditis with the Melody valve. I heard our pediatric cardiologists talk about that and telling me that it is benign, it can be cured with medical treatment in most cases, but here you had 2 out of 6 patients actually dying from it, and you had only $50 \%$ success with medical treatment. You also mentioned somewhere that you had multivalvular endocarditis in some of these cases. Was that the reason why you failed to treat these patients?

Dr Alassas. The 2 patients who died had multivalve involvement. One patient had all 4 valves involved with very aggressive endocarditis, and probably the reason for this death was that the patient presented late, and the endocarditis had already spread and involved all 4 valves. Another patient also had left-sided valves involved with Staphyloccus aureus endocarditis, but it started at the pulmonary valve and spread to the mitral valve with perforation and severe mitral regurgitation, and this patient also did not do well.

Those who required reintervention had fungal Aspergillus endocarditis, and it was mandatory to do explantation of the valve. It was also difficult to diagnose these patients who went to surgery because of their very high pressure gradients across the valves, which points to the fact detection of infective endocarditis of the pulmonary valve is sometimes difficult by transthoracic and even by transesophageal echo, which leads to a late diagnosis.

Dr Pettersson. The next thing we need to talk about is what to do surgically when you have to operate on these patients. I think it is very discouraging that you had only one-third of the patients with a satisfactory valve at 5 years. Associated with that question is the question of what is the ideal platform for you to help us out?

Dr Alassas. It is difficult to answer this question. This study sheds light on the importance of patient selection 
for which procedure to undergo. For certain patients who have a high risk for infective endocarditis, maybe we should avoid offering them transcatheter pulmonary valve replacement. Of course, for surgical pulmonary valve replacement, the homograft is the ideal choice.

Dr Pettersson. Do you think that a prosthetic valve is a better platform for you than a homograft?

Dr Alassas. In the pulmonary position?

Dr Pettersson. Yes, I am asking.

Dr Alassas. I think a homograft is still the best choice.

Dr Pettersson. Our cardiologists say differently. They want us to put in bioprosthetic valves.
The final question relates to the condition of the autograft. How perfect are the autografts in these patients that you take on percutaneously?

Dr Alassas. For those patients who have transcatheter pulmonary valve replacement, none had severe disease, only a few; $13 \%$ had moderate pulmonary regurgitation, and none had significant pulmonary stenosis. That's why they had only an isolated pulmonary transcatheter procedure. On the other hand, those who had surgical pulmonary valve replacement, 12 patients, which represents $29 \%$ of the patients, had concomitant significant aortic valve disease.

Dr Pettersson. Thank you. 